\title{
Pneumo-políticas en salud pública y aphrología
}

\author{
PNeumo-POlitics In PUblic heAlth AND APHROLOGY
}

La reciente ley del tabaco y el primer año de la ley de alcoholes, comparten una efectividad medible, un buen grado de aceptación colectiva y están basadas en resultados de investigaciones realizadas en la Escuela de Salud Pública de la Universidad de Chile, trabajo que ha sido evaluado como de notable calidad.

Aunque la legislación tiene un flanco discutible, por su sesgo hacia prácticas de policía sanitaria, masivamente basadas en controles, vigilancias, castigos y multas, la abismante toxicidad de lo que bebemos y respiramos, las ha transformado en soluciones predilectas y de mínima disidencia.

Mientras ambas leyes despliegan sus efectos, humea como un cigarrillo de ciencia ficción del siglo XIX, la chimenea de la fundición de Codelco en Ventanas. La presencia o ausencia de tabiques en las casas de Campiche o La Greda no es considerada respecto del aire de esos ciudadanos. Las aguas de Lampa o el aire de Arica, escrutados con métodos semejantes, por los mismos equipos de trabajo, no han producido ordenamientos similares para esos lugares.

La bifurcación tan marcada de los resultados de investigaciones de salud pública, pone como materia de debate las formas de articulación política de nuestras prácticas. De las condiciones que en uno y en otro caso, logran o fracasan en la implementación de regulaciones radicales. En ambos casos, los actores comprometidos son vigorosos y fuertes. La imposibilidad de una ofensiva contra CODELCO es del mismo orden de magnitud que la emprendida contra las tabacaleras. Y sin embargo, una de ellas ha sido posible.

Aunque se discute si estamos ya ante el inicio del antropoceno como era geológica nueva, me parece que los efectos antrópicos sobre este pequeño lugar que habitamos, son el problema principal de nuestra disciplina. Estudiar ese efecto, obliga a incluir la investigación sobre la acción política del antropos, como parte del estudio de salud pública. No para disolver en un solo ámbito, problemas que engarzan diferentes criterios y formas de acuerdos, sino para poder pasar del abordaje de uno y otro problema, en forma comprensible y juiciosa.

Yuri Carvajal

Escuela de Salud Pública, Facultad de Medicina, Universidad de Chile ycarvajal@uchile.cl
Sloterdijk nos invita a leer las espumas "como teoría tecnológica de espacios humanamente habitados, simbólicamente climatizados, es decir, como instrucción científica-ingeniera y política para la construcción y mantenimiento de unidades civilizatorias".

A esta aphrología o poliesferología también somos convocados. 